\title{
PERANAN PENGGUNAAAN DISCLOSING AGENT SEBELUM MENYIKAT GIGI TERHADAP PENURUNAN INDEKS PLAK PADA MURID KELAS V SD NEGERI 067247 JL. BUNGA MALEM VII KELURAHAN LAU CIH KECAMATAN MEDAN TUNTUNGAN TAHUN 2015
}

\author{
Nelly Katharina Manurung \\ Jurusan Keperawatan Gigi
}

\begin{abstract}
Abstrak
Menyikat gigi merupakan salah satu upaya yang dilakukan untuk mencegah terjadinya penumpukan plak pada permukaan gigi. Agar penyikatan gigi lebih efektif dibutuhkan bahan pewarna disclosing agent untuk menunjukkan sisa makanan dan plak yang masih tertinggal pada permukaan gigi sewaktu menyikat gigi. Penelitian bersifat deskriftif dengan metode survey yang bertujuan untuk mengetahui peranan penggunaan disclosing agent sebelum menyikat gigi terhadap penurunan indeks plak pada murid kelas V SD Negeri 067247 Jl. Bunga Malem VII Kelurahan Lau Cih Kecamatan Medan Tuntungan. Data diperoleh melalui pemeriksaan secara langsung pada murid. Sampel penelitian yaitu seluruh murid kelas $\mathrm{V}$ yang berjumlah 30 orang. Hasil penelitian diperoleh bahwa rata-rata indeks plak sebelum menyikat gigi tanpa menggunakan disclosing agent sebesar 1,95 dan sesudah menyikat gigi tanpa disclosing agent menurun menjadi 0,7. Sedangkan rata-rata indeks plak sebelum menyikat gigi dengan menggunakan disclosing agent sebesar 2,21 menurun menjadi 0,5 sesudah menyikat gigi dengan menggunakan disclosing agent. Berdasatkan tingkat kebersihan mulut pada murid kelas $\mathrm{V}$ sebelum menyikat gigi tanpa disclosing agent diperoleh kriteria baik 1 orang $(3,3 \%)$, kriteria sedang 13 orang $(43,3 \%)$ dan buruk 16 orang (53,3\%). Sesudah menyikat gigi tanpa disclosing agent diperoleh kriteria baik 22 orang $(73,4 \%)$, sedang 6 orang (20\%) dan buruk 2 orang $(6,6 \%)$. Tingkat kebersihan mulut pada murid kelas $\mathrm{V}$ sebelum menyikat gigi dengan menggunakan disclosing agent tidak ada kriteria baik, kriteria sedang 8 orang $(26,7 \%)$ dan kriteria buruk 22 orang $(73,3 \%)$. Sesudah dilakukan penyikatan gigi dengan menggunakan disclosing agent tingkat kebersihan mulut meningkat dengan kriteria baik 28 orang $(93,3 \%)$, sedang 1 orang $(3,3 \%)$ dan buruk 1 orang $(3,3 \%)$. Berdasarkan ratarata indeks plak dan kriteria indeks plak, bahwa menyikat gigi dengan menggunakan disclosing agent lebih efektif menghilangkan plak dibandingkan menyikat gigi tanpa menggunakan disclosing agent.
\end{abstract}

Kata kunci : Menyikat gigi, disclosing agent dan indeks plak

\section{PENDAHULUAN}

\section{Latar Belakang}

Kesehatan merupakan bagian penting dari setiap kehidupan manusia. Pemerintah membuat suatu program yang bertujuan untuk mengubah perilaku masyarakat kearah perilaku sehat. Perilaku ini merupakan salah satu faktor pendukung untuk mencapai kesehatan yang optimal. Perilaku sehat dan kemampuan masyarakat untuk memilih dan mendapatkan pelayanan kesehatan yang bermutu sangat menentukan pembangunan kesehatan.

Pembangunan kesehatan bertujuan meningkatkan kesadaran, kemauan, serta kemampuan hidup sehat bagi setiap orang agar terwujud derajat kesehatan yang optimal. Oleh karena itu perlu perwujudan paradigma sehat yang mengutamakan pencegahan (preventif), peningkatan kesehatan (promotif) serta upaya peningkatan (kuratif) dan pemulihan kesehatan (rehabilitatif).

Tubuh yang sehat tidak lepas keadaan rongga mulut yang sehat. Kesehatan rongga mulut merupakan bagian integral dari kesehatan manusia seutuhnya juga dalam meningkatkan kualitas dan produktivitas sumber daya manusia. Walaupun demikian banyak juga orang yang tidak tahu bahwa rongga mulut adalah organ yang berperan penting dalam kesehatan tubuh.

Menurut Hasil Survey Kesehatan Rumah Tangga (SKRT) menyatakan 39\% penduduk Indonesia menderita penyakit gigi dan mulut. Angka itu bukan merupakan angka yang dapat diabaikan karena terbukti bahwa penyakit gigi dan mulut dapat mempengaruhi produktivitas masyarakat dan tingkat prevalensi karies gigi di Indonesia mencapai 90,05\%. Karies merupakan salah satu bukti tidak terawatnya kesehatan gigi dan mulut masyarakat.

Mulut merupakan suatu tempat yang sangat ideal untuk perkembangan bakteri. Bila tidak dibersihkan dengan sempurna sisa makanan yang terselip bersama bakteri akan melekat pada gigi dan akan menumpuk di permukaan gigi dan membentuk suatu koloni yang disebut dengan plak. 
Salah satu upaya yang dapat dilakukan untuk mencegah agar tidak terjadi penumpukan plak adalah menyikat gigi. Agar hasil penyikatan gigi lebih efektif dibutuhkan bahan pewarna plak yang disebut dengan disclosing agent yang berguna untuk melihat plak dan sisa makanan yang masih terdapat pada permukaan gigi.

Bahan disclosing agent belum terlalu dikenal oleh masyarakat luas, bahkan sebagian dari masyarakat tidak pernah melihat atau menggunakan bahan disclosing agent untuk itu perlu dilakukan penyuluhan kesehatan gigi dan mulut pada masyarakat dan murid SD tentang peranan disclosing agent terhadap kesehatan gigi dan mulut.

Berdasarkan uraian diatas peneliti tertarik untuk meneliti bagaimana peranan penggunaan disclosing agent dalam menyikat gigi terhadap penurunan indeks plak.

\section{Rumusan Masalah}

Dari uraian diatas permasalahan yang hendak peneliti teliti yaitu bagaimana peranan penggunaan disclosing agent sebelum menyikat gigi terhadap penurunan indeks plak pada murid kelas V SD Negeri 067247 Jln.Bunga Malem VII kelurahan Lau Cih Kecamatan Medan Tuntungan.

\section{Tujuan Penelitian}

1. Untuk mengetahui rata-rata indeks plak sebelum dan sesudah menyikat gigi tanpa dan dengan menggunakan disclosing agent pada murid kelas $\mathrm{V}$ SD Negeri 067247 Jl. Bunga Malem Kelurahan Lau Cih Kecamatan Medan Tuntungan.

2. Untuk mengetahui penurunan indeks plak sebelum dan sesudah menyikat gigi tanpa dan dengan menggunakan disclosing agent pada murid kelas $\mathrm{V}$ SD Negeri 067247 Jl. Bunga Malem Kelurahan Lau Cih Kecamatan Medan Tuntungan.

3. Untuk mengetahui tingkat kebersihan mulut sebelum dan sesudah menyikat gigi tanpa dan dengan menggunakan disclosing agent pada murid kelas V SD Negeri 067247 Jl. Bunga Malem Kelurahan Lau Cih Kecamatan Medan Tuntungan.

\section{Manfaat Penelitian}

1. Hasil penelitian ini diharapkan dapat menambah pengetahuan dan sumber informasi bagi pihak sekolah mengenai kesehatan gigi dan mulut.

2. Hasil penelitian ini diharapkan dapat menambah wawasan murid kelas $\mathrm{V}$ tentang menyikat gigi dan pentingnya penggunaan disclosing agent sebelum menyikat gigi.

3. Hasil penelitian ini diharapkan dapat menjadi sumber informasi atau sumber data bagi peneliti berikutnya.

\section{METODOLOGI PENELITIAN}

\section{Jenis Dan Desain Penelitian}

Jenis penelitian yang dilakukan adalah penelitian deskriptif dengan metode survey, penelitian ini bertujuan untuk mengetahui peranan disclosing agent sebelum menyikat gigi terhadap penurunan indeks plak pada murid kelas V SD Negeri 067247 Kelurahan Lau cih Kecamatan Medan Tuntungan.

\section{Populasi}

Populasi adalah keseluruhan subjek penelitian (Arikunto, 2006). Populasi dalam penelitian ini adalah murid SD Negeri 067247 Jl.Bunga Malem VII Kelurahan Lau Cih Kecamatan Medan Tuntungan.

\section{Sampel}

Sampel adalah pengambilan sebagian dari keseluruhan subjek yang diteliti dan dianggap mewakili seluruh populasi (Notoatmodjo,S, 2002). Sampel penelitian yang diambil adalah keseluruhan murid kelas V SD Negeri 067247 yang berjumlah 30 orang.

\section{HASIL DAN PEMBAHASAN}

\section{Hasil Penelitian}

Berdasarkan penelitian yang telah dilakukan, maka diperoleh skor indeks plak sebelum dan sesudah menyikat gigi dengan menggunakan disclosing agent dan tanpa menggunakan disclosing agent pada 30 murid kelas V SD Negeri 067247 Kelurahan Lau Cih Kecamatan Medan Tuntungan tahun 2015.

Tabel 1. Karakteristik Murid-Murid Kelas V SDN 067247 Kelurahan Lau Cih Kecamatan Medan Tuntungan Berdasarkan Jenis Kelamin

\begin{tabular}{ccc}
\hline Jenis kelamin & $\begin{array}{c}\text { Jumlah } \\
(\mathbf{n})\end{array}$ & $\begin{array}{c}\text { Persentase } \\
(\boldsymbol{\%})\end{array}$ \\
\hline Laki-laki & 19 & 63,3 \\
Perempuan & 11 & 36,7 \\
\hline
\end{tabular}

Dari tabel 1 di atas menunjukkan persentase murid berdasarkan jenis kelamin didapatkan laki-laki sebanyak 19 orang atau sebesar 63,3\% sedangkan perempuan sebanyak 11 orang atau sebesar $36,4 \%$.

Tabel 2. Distribusi Frekuensi Rata-Rata Indeks Plak Sebelum dan Sesudah Tindakan Menyikat Gigi tanpa Mengunakan Disclosing Agent pada Murid Kelas V SD Negeri 067247 Kelurahan Lau Cih Kecamatan Medan Tuntungan Tahun 2015

\begin{tabular}{ccc}
\hline \multirow{2}{*}{$\begin{array}{c}\text { Jumlah } \\
\text { murid }\end{array}$} & \multicolumn{2}{c}{ Rata- rata Indeks Plak } \\
\cline { 2 - 3 } & $\begin{array}{c}\text { Rata-rata } \\
\text { Sebelum }\end{array}$ & Rata- rata Sesudah \\
\hline 30 orang & 1,95 & 0,7 \\
\hline
\end{tabular}

Dari tabel 2 menunjukkan rata-rata indeks plak ssebelum dan sesudah menyikat gigi tanpa menggunakan disclosing agent, dimana rata-rata indeks plak sebelum menyikat gigi sebesar 1,97 menurun menjadi 0,7 sesudah dilakukan tindakan menyikat gigi tanpa menggunakan disclosing agent. 
Tabel 3. Distribusi Frekuensi Rata-Rata Indeks Plak Sebelum dan Sesudah Tindakan Menyikat Gigi dengan Mengunakan Disclosing Agent pada Murid Kelas V SD Negeri 067247 Kelurahan Lau Cih Kecamatan Medan Tuntungan Tahun 2015

\begin{tabular}{ccc}
\hline \multirow{2}{*}{\begin{tabular}{c} 
Jumlah \\
\cline { 2 - 3 }
\end{tabular}} & \multicolumn{2}{c}{ Rata- rata Indeks plak } \\
\cline { 2 - 3 } & $\begin{array}{c}\text { Rata-rata } \\
\text { Sebelum }\end{array}$ & Rata-rata Sesudah \\
\hline 30 & 2,21 & 0,5 \\
\hline
\end{tabular}

Dari tabel 3 dapat dilihat bahwa terjadi penurunan indeks plak pada 30 murid SD Negeri 067247 dengan rata-rata sebelum menyikat gigi sebesar 2,21 dan sesudah dilakukan tindakan menyikat gigi dengan menggunakan disclosing agent menjadi 0,7.

Tabel 4. Distribusi Frekuensi Persentase Tingkat Kebersihan Mulut Sebelum Menyikat Gigi tanpa Menggunakan Disclosing Agent pada Murid Kelas V SD Negeri 067247 Kelurahan Lau Cih Kecamatan Medan Tuntungan Tahun 2015

\begin{tabular}{ccc}
\hline Kriteria & $\begin{array}{c}\text { Jumlah } \\
(\mathbf{n})\end{array}$ & $\begin{array}{c}\text { Persentase } \\
(\mathbf{\%})\end{array}$ \\
\hline Baik & 1 & 3,3 \\
Sedang & 13 & 43,3 \\
Buruk & 16 & 53,4 \\
\hline Jumlah & 30 & 100 \\
\hline
\end{tabular}

Tabel 4 menunjukkan persentase kebersihan mulut sebelum menyikat gigi tanpa menggunakan disclosing agent dengan kriteria baik 1 orang (3,3\%), sedang 13 orang $(43,3 \%)$, dan buruk 16 orang $(53,3 \%)$.

Tabel 5. Distribusi Frekuensi Persentase Kebersihan Mulut Sesudah Tindakan Menyikat Gigi tanpa Menggunakan Disclosing Agent pada Murid Kelas V SD Negeri 067247 Kelurahan Lau Cih Kecamatan Medan Tuntungan Tahun 2015

\begin{tabular}{ccc}
\hline Kriteria & $\begin{array}{c}\text { Jumlah } \\
(\mathbf{n})\end{array}$ & $\begin{array}{c}\text { Persentase } \\
(\boldsymbol{\%})\end{array}$ \\
\hline Baik & 22 & 73,4 \\
Sedang & 6 & 20 \\
Buruk & 2 & 6,6 \\
\hline Jumlah & 30 & 100 \\
\hline
\end{tabular}

Dari tabel 5 diperoleh bahwa persentasse kebersihan mulut sesudah menyikat gigi tanpa menggunakan disclosing agent dengan kriteria baik 22 orang $(73,4 \%)$, sedang 6 orang $(20 \%)$ dan buruk 2 orang $(6,6 \%)$
Tabel 6. Distribusi Frekuensi Persentase Tingkat Kebersihan Mulut Sebelum Tindakan Menyikat Gigi dengan Menggunakan Disclosing Agent pada Murid Kelas V SD Negeri 067247 Kelurahan Lau Cih Kecamatan Medan Tuntungan Tahun 2015

\begin{tabular}{ccc}
\hline Kriteria & $\begin{array}{c}\text { Jumlah } \\
(\mathbf{n})\end{array}$ & $\begin{array}{c}\text { Persentase } \\
(\boldsymbol{\%})\end{array}$ \\
\hline Baik & 0 & 0 \\
Sedang & 8 & 26,7 \\
Buruk & 22 & 73,3 \\
\hline Jumlah & 30 & 100 \\
\hline
\end{tabular}

Tabel 6 menunjukkan persentase kebersihan mulut sebelum menyikat gigi dengan menggunakan disclosing agent dengan kriteria baik tidak ditemukan $(0 \%)$, sedang 8 orang $(26,7 \%)$ dan buruk 22 orang $(73,3 \%)$.

Tabel 7. Distribusi Frekuensi Persentase Tingkat Kebersihan Mulut Sesudah Tindakan Menyikat Gigi dengan Menggunakan Disclosing Agent pada Murid Kelas V SD Negeri 067247 Kelurahan Lau Cih Kecamatan Medan Tuntungan Tahun 2015

\begin{tabular}{ccc}
\hline Kriteria & $\begin{array}{c}\text { Jumlah } \\
(\mathbf{n})\end{array}$ & $\begin{array}{c}\text { Persentase } \\
(\mathbf{\%})\end{array}$ \\
\hline Baik & 28 & 93,3 \\
Sedang & 1 & 3,3 \\
Buruk & 1 & 3,4 \\
\hline Jumlah & 30 & 100 \\
\hline
\end{tabular}

Tabel 7 menunjukkan bahwa kebersihan mulut sesudah menyikat gigi dengan menggunakan disclosing agent dengan kriteria baik 28 orang (93,3\%), sedang 1 orang $(3,3 \%)$ dan buruk 1 orang $(3,3 \%)$.

\section{Pembahasan}

Berdasarkan tabel 2 distribusi frekuensi rata-rata indeks plak sebelum dan sesudah tindakan menyikat gigi tanpa menggunakan disclosing agent diperoleh rata-rata indeks plak sebelum sebesar 1,95 menurun menjadi 0,7 setelah tindakan menyikat gigi. Berdasarkan penurunan tersebut bahwa dengan hanya menyikat gigi dapat menurunkan indeks plak. Hal ini sesuai dengan pendapat Srigupta (2004), yang mengatakan bahwa menyikat gigi merupakan salah satu upaya cara pengontrolan plak secara mekanik.

Berdasarkan tabel 3 distribusi frekuensi rata-rata indeks plak sebelum dan sesudah tindakan menyikat gigi menggunakan disclosing agent diperoleh rata-rata indeks plak sebelum menyikat gigi sebesar 2,21 menurun menjadi 0,5 setelah menyikat gigi dengan menggunakan disclosing agent. Sesuai dengan pendapat Hartzell (1930), yang dinyatakan dalam Jurnal of the American bahwa penggunaan disclosing agent sangat berguna dalam evaluasi diri agar pengontrolan plak yang dilakukan lebih efektif. Hal ini sesuai dengan pendapat Pintauli, S (2008), yang mengatakan bahwa disclosing agent digunakan untuk mengevaluasi penyikatan gigi yang sudah dilakukan. 
Berdasarkan tabel 4 dan tabel 5 distribusi frekuensi persentase tingkat kebersihan mulut sebelum dan sesudah tindakan menyikat gigi tanpa menggunakan disclosing agent, bahwa jumlah responden yang memiliki kebersihan mulut dengan kriteria baik sebelum menyikat gigi tanpa disclosing agent hanya 1 orang $(3,3 \%)$ dan untuk kriteria buruk ada 16 orang (53,3 \%). Hal ini menunjukkan bahwa lebih dari setengah jumlah responden kurang menjaga kebersihan mulut terutama dalam menyikat gigi. Sesudah dilakukan tindakan menyikat gigi dengan menggunakan disclosing agent untuk kriteria baik pada responden yaitu 22 orang $(83,3 \%)$ dan untuk kriteria buruk 2 orang $(6,6 \%)$. Setelah dilakukan penyikatan gigi tingkat kebersihan mulut menjadi meningkat hal ini dipengaruhi oleh cara dan teknik menyikat gigi yang sudah tepat. Selain itu juga dipengaruhi oleh faktor dan waktu menyikat gigi. Menurut Panjaitan, M (1995), frekuensi yang baik dalam menyikat gigi yaitu dua kali sehari pagi seesudah sarapan dan malam sebelum tidur.

Berdasarkan tabel 6 distribusi frekuensi persentase tingkat kebersihan mulut sebelum tindakan menyikat gigi dengan menggunakan disclosing agent dapat diperoleh bahwa tidak ada responden yang memiliki kriteria baik dan untuk kriteria buruk 22 orang (73,3\%). Berdasarkan data tersebut diperoleh bahwa lebih dari setengah jumlah responden kurang memperhatikan kebersihan mulut. Hal ini dimungkinkan karena kurangnya pengetahuan responden tentang cara pemeliharaan kebersihan mulut. Sesuai dengan pendapat Pintauli, S (2008), yang mengatakan salah satu cara pemeliharaan kebersihan gigi dan mulut adalah dengan menyikat gigi yang bertujuan untuk menyingkirkan plak dan mencegah terjadinya penumpukan plak, membersihkan sisa-sisa makanan atau debris dan melapisi permukaan gigi dengan fluor. Sesuai dengan pendapat Pratiwi, D (2005), bahwa dalam menyikat gigi perlu diperhatikan pasta gigi yang digunakan yaitu pasta gigi yang mengandung fluor.

Berdasarkan tabel 7 distribusi frekuensi persentase tingkat kebersihan mulut sesudah tindakan menyikat gigi dengan menggunakan disclosing agent untuk kriteria baik mengalami peningkatan menjadi 28 orang $(93,3 \%)$ dan untuk kriteria buruk menurun menjadi 1 orang $(3,3 \%)$. Penurunan yang terjadi dimungkinkan oleh penggunaan disclosing agent sebelum menyikat gigi pada responden. Disclosing agent dapat digunakan untuk membantu seseorang dalam melihat area permukaan gigi yang belum bersih sewaktu menyikat gigi. Jika teknik dan cara menyikat gigi belum tepat, maka muncul tanda yang berwarna kemerah-merahan pada bagian permukaan gigi yang menunjukkan masih adanya sisa makanan atau plak. Sehingga dapat memudahkan seseorang dalam membersihkan gigi geligi.

Dari hasil penelitian diperoleh bahwa adanya perbedaan penurunan indeks plak dalam menyikat gigi tanpa menggunakan disclosing agnet dan dengan menggunakan disclosing agent.

\section{SIMPULAN DAN SARAN}

\section{Simpulan}

Dari hasil penelitian yang dilakukan pada 30 murid kelas V SD Negeri 067247 Kelurahan Lau Cih Kecamatan Medan Tuntungan dapat disimpulkan sebagai berikut:

1. Indeks plak rata-rata sebelum tindakan menyikat gigi tanpa menggunakan disclosing agent adalah sebesar 1,95 menurun menjadi 0,7 sesudah menyikat gigi tanpa menggunakan disclosing agent. Terjadi penurunan indeks plak sebesar 1,25

2. Indeks plak rata-rata sebelum tindakan menyikat gigi dengan menggunakan disclosing agent adalah sebesar 2,21 menurun menjadi 0,5 setelah tindakan menyikat gigi dengan menggunakan disclosing agent.

Terjadi penurunan indeks plak 1,71

3. Kebersihan mulut sebelum tindakan menyikat gigi tanpa menggunakan disclosing agent, untuk kriteria baik yaitu 1 orang $(3,3 \%)$, sedang 13 orang $(43,3 \%)$ dan buruk 16 orang $(53,4 \%)$. Setelah dilakukan tindakan menyikat gigi tanpa disclosing agent untuk kriteria baik mengalami peningkatan menjadi 22 orang $(83,3 \%)$, dan untuk kriteria sedang menurun menjadi 6 orang $(20 \%)$ orang serta kriteria buruk menjadi 2 orang $(6,6 \%)$.

4. Kriteria baik untuk kebersihan mulut sebelum tindakan menyikat gigi dengan menggunakan disclosing agent tidak dijumpai, kriteria sedang 8 orang $(26,7 \%)$ dan kriteria buruk 22 orang(73,3\%). Sesudah dilakukan tindakan menyikat gigi dengan menggunakan disclosing agent untuk kriteria baik mengalami peningkatan menjadi 28 orang $(93,3 \%)$, kriteria sedang menurun menjadi 1 orang $(3,3 \%)$ serta untuk kriteria buruk menjadi 1 orang $(3,3 \%)$.

5. Berdasarkan rata-rata indeks plak dan kriteria indeks plak, bahwa menyikat gigi dengan menggunakan disclosing agent lebih efektif menghilangkan plak dibandingkan menyikat gigi tanpa menggunakakan disclosing agent.

\section{Saran}

1. Diharapkan kepada orang tua murid agar lebih memperhatikan kesehatan gigi dan mulut terutama dalam tindakan menyikat gigi yang tepat.

2. Diharapkan kepada murid kelas V SD Negeri 067247 Kelurahan Lau Cih Kecamatan Medan Tuntungan agar menjaga kesehatan gigi dan mulut serta membiasakan diri dalam menyikat gigi dengan cara dan teknik yang tepat.

3. Diharapkan kepada pihak sekolah dasar agar menjalin kerja sama dengan pihak Puskesmas setempat dalam pemeliharaan kesehatan gigi dan mulut pada murid SD Negeri 067247 Kelurahan Lau Cih Kecamatan Medan Tuntungan melalui Program Usaha Kesehatan Gigi Sekolah.

4. Diharapkan kepada pihak pelayanan kesehatan khususnya bidang kesehatan gigi dan mulut agar melakukan penyuluhan tentang menyikat gigi yang 
baik dan benar serta peranan penggunaan disclosing agent dalam penyikatan gigi.

\section{DAFTAR PUSTAKA}

Arikunto, S, 2006, Posedur Penelitian Suatu Pendekatan Praktik, Rineka Cipta, Jakarta.

Forrest, JO, 1995, Pencegahan Penyakit Mulut, Edisi II, Hipokrates, Jakarta.

Dalimunthe, SH, 2006, Terapi Periodontal, Departemen Periodonsia FKG USU, Medan.

Megananda, dkk, 2010, Ilmu Pencegahan Penyakit Jaringan Keras dan Jaringan Pendukung Gigi, buku kedokteran EGC, Jakarta.

Notoatmodjo, S, 2002, Metodologi Penelitian Kesehatan, Rineka Cipta, Jakarta.
Panjaitan, M, 1995, Etiologi Karies Gigi dan Penyakit Periodontal, USU Press, Medan.

Ilmu Pencegahan Karies

Gigi, USU Press, Medan

Pintauli, S, 2008, Mепији Gigi dan Mulut Sehat, USU Press, Medan.

Pratiwi, D, 2005, Gigi Sehat, Buku Kompas, Jakarta.

Srigupta, 2004, Perawatan Gigi dan Mulut, Prestasi Pustaka, Jakarta.

Suwelo, Ismu S, 1995, Petunjuk Praktis Sistem Merawat Gigi Anak di Klinik, buku kedokteran EGC, Jakarta

http://www.pdgi-online.com, Maret, 2011. 